\title{
Sex differences in prevalence rates and predictors of cigarette smoking among in-school adolescents in Kilimanjaro, Tanzania
}

\author{
S. SIZIYA', P.R.T. NTATA², E. RUDATSIKIRA ', C.M. MAKUPE', E. UMAR', and A.S. MUUL \\ 'Department of Community Medicine, School of Medicine. Lniversity of Zambia, P.O. 50110. Lusaka. Zambia \\ ¿Department of Saciologi: Chanedlor College. Linversity of Malawi, Zomba. Malawi \\ SSchool of Public Health. Loma Linda Liniversitv: Loma Linda. California. USA \\ "Department of Demographl and Population Studies. Chancellor College. Lniversity of Malawi, Zomba. Malavi \\ Department of Community Health. College of Medicine. Lniversity of Malawi, Blantre. Malawi
}

\begin{abstract}
An analysis of the Global Youth Tobacco Survey for Kilimanjaro, Tanzania was carried out to assess sex differences in the prevalence rates and predictors of current cigarette smoking among in-school adolescents. A total of 2323 adolescents participated in the study of whom $53 \%$ were females and $47 \%$ males. The prevalence of current cigarette smoking was $3.0 \%$ and $1.4 \%$ among males and females, respectively. The common factors that were significantly positively associated with cigarette smoking between sexes were: having more pocket money, closest friend smoked cigarettes, seeing actors smoke on TV, videos or movies, and seeing advertisements for cigarettes at social gatherings. Seeing anti-smoking messages at social gatherings were negatively associated with smoking among both sexes. While having had something such as a 1-shirt or pen with a cigarette brand logo on it was positively associated with cigarette smoking among inales, it was negatively associated with cigarette smoking among females. Male adolescents older than 15 years, those in their $9^{\text {th }}$ year of schooling, and those who had seen cigarette brand names on TV were more likely 10 smoke. Meanwhile, male respondents who were in their $8^{t}$ year of schooling, had seen anti-smoking media messages, and advertisements for cigarettes in newspapers or magazines were less likely to smoke. Among female adolescents, those who had parents who smoked, and surprisingly those who perceived that cigarette smoking as harmful were more likely to snoke. Interestingly, seeing advertisement for cigarettes on billboards was negatively associated with smoking among female adolescents. Interventions aimed to reduce adolescent smoking need to be designed and implemented with due consideration of sex differences in these associated factors.
\end{abstract}

Keywords: adolescent lyealth, cigarette smoking, Kilimanjaro, Tanzania

\section{Introduction}

Cigarette smoking is among leading causes of morbidity and mortality in the world. Total tobacco-attributable deaths are projected to rise from 5.4 million in 2005 to 6.4 million in 2015 and 8.3 million in 2030 (Mathers \& Loncar, 2006). Many adult smokers initiate smoking either as young adults or adolescents (CDC, 2006; Patton et al., 2006). Adolescent smoking is also of public health interest as it is associated with immediate or short-term consequences such as exacerbation of asthma and increased risk for respiratory infections (Gilliland et al., 2006). Adolescent smokers are also likely to engage in other unhealthy or harmful lifestyles such as illieit drug use, teen sex, alcohol use and truancy (Weden \& Zabin, 2005; Kokkevi et al.. 2007; Myers et al., 2007).

An association between adolescent smoking and peer and or parental smoking has been previously reported (Brook et al., 2006; Bricker et al., 2007). Studies on eigarette smoking among adolescents in sub-Saharan Africa have reported on the prevalence of exposure to both pro- and anti-tobaceo smoking (Mpabulungi \& Muula, 2004; 2006). Tobacco use among adolescents is a growing problem in Kilimanjaro region, Tanzania.
In order to inform the targeting of at risk individuals in the design and implementation of anti-smoking intervention efforts, there is need to asscss whether there exists an association between selected sociodemographic variables and adolescent smoking in Africa. No previous studies on cigarette smoking we are aware of have ever been done in the region, and in particular to assess sex differences in smoking prevalence rates and associated factors. This study was therefore carried out to estimate the prevalence of current cigarette smoking and the associated factors between sexes among in-school adolescents in Kilimanjaro, Tanzania in 2003.

\section{Materials and Methods}

\section{Study area and design}

The study was conducted in Kilimanjaro region in northern Tanzania. All schools in the region with Classes 6 and 7 and Form I and 11 (6 to 9 years of schooling) were eligible to take part in the study. This study involved secondary analysis of data from the Global Youth Tobacco Survey (GYTS) conducted in the region in 2003. The GYTS is an in-school survey that uses a standard methodology for constructing the sampling frame, selecting schools and classes, preparing questionnaires, following consistent field procedures, and using consistent data management 
procedures for data processing and analysis (Warren et al. 2000).

Data were collected in a survey that used a two-stage probability sampling technique. Primary sampling units were schools which were selected with a probability proportional to their enrolment size. In the second step of sampling, a systematic sample of classes in the selected school was obtained. All students in the selected classes were eligible to participate. A self-completed questionnaire was used. Completion of question occurred within one class period and trained research assistants supervised the process.

\section{Variables considered in the analysis}

The main outcome variable was current cigarette smoking defined as having smoked a cigarette, even a single puff, within 30 days preceding the survey. Study participants were asked on how many days they smoked cigarettes. A response of zero days was recoded as 'not a current smoker' while a response of any number of days of smoking was recoded as a current smoking.

Independent variables included age, year of schooling, whether the adolescent usually had pocket money, smoking status of parents and close friends. Other variables were whether study participants had secn anti-smoking media messages; seen anti-smoking messages at social gatherings; seen actors smoking on television (TV), videos or movies; had item such as a $\mathrm{t}$-shirt or pen with a cigarette brand $\operatorname{logo}$ on it; seen cigarette brand names on TV; seen advertisements for eigarettes on billboards; seen advertisements for eigarettes in ncwspapers or magazines and; seen advertisements for cigarettes at social gatherings. Study participants were also asked whether they perceived cigarette smoking as harmful to health.

\section{Data analysis}

Data was analysed to determine the prevalence and associated factors of cigarette smoking between sexes among adolescents. A weighting factor was used in the analysis to reflect the likelihood of sampling each student and to reduce bias by compensating for differing patterns of non response. The weight used for estimation is given by the following formula as described by The GTSS Collaborative Group (2006) and Kyrlesi ef al. (2007):
$W^{\prime}=W_{1} * W_{2} * f_{1} * f_{2} * f_{3} * f 4$

Where:

$W 1=$ the inverse of the probability of selecting the school

$\mathrm{W}_{2}=$ the inverse of the probability of selecting the classroom within the school

$f 1=$ a school-level non response adjustment lactor calculated by school size category (small, medium, large)

$\mathrm{f} 2=$ a class-level non response adjustment factor calculated for each school

$\mathrm{f3}=$ a student-level non response adjustment

factor calculated by class

$\mathrm{f} 4=\mathrm{a}$ post stratification adjustment factor calculated by grade

Backward logistic regression analyses to estimate the associations between relevant predictor variables and cigarette smoking within the last 30 days were done for each sex. Results for multivariate analysis (adjusted odds ratios) for the factors found significantly associated with the outcome are reported.

\section{Ethical considerations}

Permission for the data collection was obtained from the Ministry of Education. All eligible students were invited to participate. They were however free not to participate or not to complete any segments of the questionnaire if they so desired. Questionnaires were completed anonymously.

\section{Results}

A total of 2323 adolescents, $47 \%$ males and $53 \%$ females, participated in the survey. Overall prevalence of smoking was $3.0 \%$ and $1.4 \%$ among males and females, respectively. Table 1 shows sociodemographic correlates for cigarette smoking between sexes among adolescents in Kilimanjaro.

The common socio-demographic factors associated with cigarette smoking between sexes were having more pocket money, and closest friend smoked cigarettes. Among the male respondents alone, adolescents of age more than 15 years were more likely to smoke cigarettes than younger ones. Compared to male adolescents in their $6^{\text {th }}$ year of schooling, those in their $8^{\text {th }}$ and $9^{\text {th }}$ years of schooling were less and more likely, respectively, to smoke cigarettes. Parental smoking was significantly associated with cigarette smoking among only female respondents. 
Table 1: Prevalence and associated socio-demographic factors of cigarette smoking adolescents in Kilimanjaro

\begin{tabular}{|c|c|c|c|c|}
\hline \multirow[t]{2}{*}{ Factor } & \multicolumn{2}{|c|}{ Males } & \multicolumn{2}{|c|}{ Female } \\
\hline & $n(\%)^{a}$ & OR $(95 \% \mathrm{CI})^{b}$ & $n(\%)^{a}$ & OR $(95 \% \mathrm{Cl})^{\mathrm{b}}$ \\
\hline Age (years) & $123(2.3)$ & 1 & $173(2.9)$ & - \\
\hline$<13$ & $165(1.9)$ & $0.64(0.51,0.81)$ & $243(1.3)$ & \\
\hline 13 & $186(2.6)$ & $0.56(0.45,0.69)$ & $264(0)$ & \\
\hline 14 & $195(3.5)$ & $0.84(0.70,1.02)$ & $221(0.9)$ & \\
\hline 15 & $300(4.6)$ & $2.02(1.72,2.38)$ & $201(2.0)$ & \\
\hline \multicolumn{5}{|c|}{$\begin{array}{l}>15 \\
\text { Schooling (years) }\end{array}$} \\
\hline 6 & $300(2.6)$ & 1 & $376(1.1)$ & \\
\hline 7 & $330(2.9)$ & $11.10(0.95,1.27)$ & $447(0.6)$ & - \\
\hline 8 & $186(2.7)$ & $0.46(0.37,0.57)$ & $164(1.3)$ & \\
\hline 9 & $157(5.6)$ & $1.74(1.51,2.02)$ & $116(3.7)$ & \\
\hline \multicolumn{5}{|c|}{ Pocket money received } \\
\hline None & $795(1.8)$ & 1 & $982(0.5)$ & 1 \\
\hline$<1000$ & $100(7.0)$ & $0.87(0.75,1.02)$ & $75(5.0)$ & $0.83(0.64,1.08)$ \\
\hline $1000+$ & $68(11.4)$ & $2.22(1.93,2.55)$ & $34(15.6)$ & $14.2410 .84,18.70)$ \\
\hline \multicolumn{5}{|c|}{ Parent smoked cigarettes } \\
\hline No & $729(2.7)$ & - & $802(0.6)$ & 1 \\
\hline Yes & $216(4.1)$ & & $255(3.2)$ & $1.79(1.49,2.14)$ \\
\hline \multicolumn{5}{|c|}{ Closest friend smoked } \\
\hline No & $676(0.9)$ & 1 & $805(0.1)$ & 1 \\
\hline Yes & $288(8.5)$ & $2.62(2.39,2.87)$ & $279(3.9)$ & $2.95(2.35,3.70)$ \\
\hline
\end{tabular}

a $\%$ - weighted percentage, $n$ - un-weighted number of respondents for the entire sample and not for complete case analysis in the multivariate analyses

- $\mathrm{OR}(95 \% \mathrm{Cl})$ - adjusted odds ratios for all the factors in tables 1 to 3 in a Backward logistic regression analysis

Seeing anti-smoking messages at social gatherings was negatively associated with cigarette smoking among both male and female respondents. Furthermore, secing anti-smoking media messages was negatively associated with cigarette smoking among only male adolescents. Perception of cigarette smoking as adolescents in Kilimanjaro are shown in Table 2.

Table 3 shows factors related to advertisements that were associated with ejgarette smoking. Sceing advertisements for cigarettes at social gatherings, and seeing actors smoking on TV, videos or movies were

Table 2: Prevalence and associated anti-smoking factors of cigarette smoking adolescents in Kilimanjaro

\begin{tabular}{|c|c|c|c|c|}
\hline \multirow[t]{2}{*}{ Factor } & \multicolumn{2}{|c|}{ Males } & \multicolumn{2}{|c|}{ Females } \\
\hline & $n(\%)^{\mathrm{a}}$ & OR $(95 \% \mathrm{Cl})^{\mathrm{b}}$ & $n(\%)^{a}$ & OR $(95 \% \mathrm{Cl})^{\mathrm{b}}$ \\
\hline \multicolumn{5}{|c|}{$\begin{array}{l}\text { Seen anti-smoking media } \\
\text { messages }\end{array}$} \\
\hline No & $214(5.4)$ & 1 & $245(0.9)$ & \\
\hline Yes & $735(2.3)$ & $0.51(0.47,0.56)$ & $844(1.2)$ & - \\
\hline \multicolumn{5}{|c|}{$\begin{array}{l}\text { Seen anti-smoking } \\
\text { messages at social } \\
\text { gatherings }\end{array}$} \\
\hline No & $508(3.1)$ & 1 & $625(0.7)$ & 1 \\
\hline Yes & 447 (3.5) & $0.89(0.80,0.98)$ & $452(0.9)$ & $0.46(0.37,0.56)$ \\
\hline \multicolumn{5}{|c|}{$\begin{array}{l}\text { Cigarette smoking is harmful } \\
\text { to health }\end{array}$} \\
\hline No & $937(2.9)$ & - & $1043(0.9)$ & 1 \\
\hline Yes & $27(11.5)$ & & $41(7.2)$ & $1.64(1.27,2.12)$ \\
\hline
\end{tabular}

a $\%$ - weighted percentage, $n$ - un-weighted number of respondents for the entire sample and not for complete case analysis in the multivariate analyses; ${ }^{\circ}$ OR $(95 \% \mathrm{Cl})$ - adjusted odds ratios for all the factors in tables 1 to 3 in a Backward logistic regression analysis

harmful to health was positively associated with cigarette smoking among only female adolescents. Anti-smoking correlates for cigarette smoking among positively associated with cigarette smoking among both sexes. While having had something such as a t-shirt or pen with a cigarette brand logo on it was positively associated with cigarette smoking among 
males, it was, surprisingly, negatively associated with cigarette smoking among females. Seeing cigarette brand names on TV, videos or movies was positively associated with cigarette smoking among only males. Interestingly, seeing advertisements for cigarettes in newspapers or magazines was negatively associated with cigarette smoking among only male adolescents, and seeing advertisements for cigarettes on billboards was negatively associated with cigarette smoking among only female adolescents. current study, males were more likely to be smokers than females partly because more males than females were more likely to be outgoing to social gatherings, where temptations to smoke are great.

Pressure of examinations may have contributed to adolescents in their $9^{\text {th }}$ year of schooling to be more likely to smoke. The $8^{\text {th }}$ year of schooling is a non-examination year in Tanzania and in-school adolescents may be less likely to smoke. However, although examinations are held in the $9^{\text {ih }}$ year of schooling in Tanzania, at worst if a student fails, he/she

Table 3: Prevalence and associated advertisement factors of cigarette smoking adolescents in Kilimanjaro

\begin{tabular}{|c|c|c|c|c|}
\hline \multirow[t]{2}{*}{ Factor } & \multicolumn{2}{|c|}{ Males } & \multicolumn{2}{|c|}{ Females } \\
\hline & $\mathbf{n}(\%)^{a}$ & OR $(95 \% \mathrm{Cl})^{\mathrm{b}}$ & $\mathbf{N}(\%)^{\mathrm{a}}$ & OR $(95 \% \mathrm{Cl})^{b}$ \\
\hline \multicolumn{5}{|c|}{$\begin{array}{l}\text { Seen actors smoking on } T V \text {, videos or } \\
\text { movies }\end{array}$} \\
\hline No & $536(1.4)$ & 1 & $711(0.7)$ & 1 \\
\hline Yes & $430(4.8)$ & $1.64(1.49,1.82)$ & $386(1.6)$ & $1.38(1.12,1.69)$ \\
\hline \multicolumn{5}{|c|}{$\begin{array}{l}\text { Had something such as a t-shirt or pen } \\
\text { with a cigarette brand logo on it }\end{array}$} \\
\hline No & $743(2.7)$ & 1 & $877(0.8)$ & 1 \\
\hline Yes & $198(4.9)$ & $1.16(1.05,1.27)$ & $199(1.1)$ & $0.68(0.55,0.84)$ \\
\hline \multicolumn{5}{|c|}{ Seen cigarette brand names on TV } \\
\hline No & $532(2.2)$ & 1 & $702(0.6)$ & - \\
\hline Yes & $419(4.5)$ & $1.48(1.33,1.65)$ & $377(2.1)$ & \\
\hline \multicolumn{5}{|c|}{$\begin{array}{l}\text { Seen advertisements for cigareftes on } \\
\text { billboards }\end{array}$} \\
\hline No & $345(3.2)$ & - & $446(0.5)$ & 1 \\
\hline Yes & $606(3.2)$ & & $633(1.2)$ & $0.75(0.60,0.94)$ \\
\hline \multicolumn{5}{|c|}{$\begin{array}{l}\text { Seen advertisements for cigarettes in } \\
\text { newspapers or magazines }\end{array}$} \\
\hline No & $464(2.6)$ & 1 & $587(0.7)$ & \\
\hline Yes & $485(3.8)$ & $10.71(0.64,0.78)$ & $497(1.2)$ & - \\
\hline \multicolumn{5}{|c|}{$\begin{array}{l}\text { Seen advertisements for cigarettes at } \\
\text { social gatherings }\end{array}$} \\
\hline No & $617(2.2)$ & 1 & $741(0.5)$ & 1 \\
\hline Yes & $346(4.8)$ & $1.19(1.08,1.31)$ & $355(2.5)$ & $4.60(3.60,5.88)$ \\
\hline
\end{tabular}

a \% - weighted percentage, $\mathrm{n}$ - un-weighted number of respondents for the entire sample and not for complete case analysis in the multivariate analyses

${ }^{\circ} \mathrm{OR}(95 \% \mathrm{Cl})$ - adjusted odds ratios for all the factors in tables 1 to 3 in a Backward logistic regression analysis

\section{Discussion}

Our study has found that the prevalence of smoking was higher among males compared to females. The prevalence of current cigarette smoking in Kilimanjaro is much lower than the $16.2 \%$ reported by Kyrlesi et al. (2007) for Greek adolescents and $12.2 \%$ to $25.5 \%$ for Ugandan ones (Mpabulungi \& Muula, 2006). The finding that males were more likely to be smokers than females has been reported in other studies in diverse settings across the globe. However, an assessment of the GYTS surveys also has reported that the two sexes were equally likely to be smokers (Global Youth Tobacco Survey Collaborating Group, 2003). In the can only repeat the year of schooling. Students are not dropped from school for failing examinations in the $9^{\text {th }}$ year of schooling.

Our study also found that having closest friends as smoker and parental smoking were all associated with current smoking in the study participant. Due to the cross sectional nature of the study design and the questions asked in the survey we are unable to determine whether being a smoker attracts friends who are themselves smokers or rather that smokers preferentially select other smokers as their closest friends. It is possible that both mechanisms may be operational. The findings suggest that smoking cessation interventions targeting adolescents should 
be designed in such a way that the smoker's closest friends are also largeted.

The odds of being a current smoker among adolescents were higher if they reported parental smoking. Parental smoking may mean that the adolescent has assured access to cigarettes within the home. Also parents who smoke may not be committed to discourage adolescent smoking. Our findings demonstrate that in general exposure to pro-tobacco media is associated with being a smoker. Exposure to anti-tobacco media was associated with less likelihood of being a smoker. Other workers have reported similar findings eslewhere (Primack et al., 2006). The harmful effects of anti-tobacco advertisements from tobacco firms on adolescent smoking have been reported recently (Wakefield et al., 2006). These authors found that anti-tobacco messages directed at parents and guardians from tobacco firms in fact had the opposite effect of encouraging adolescent smoking. This suggests to us that public health policy makers should be vigilant and not just get satisfied with awareness campaigns without assessing their impact.

The linding that adolescents who believed that smoking was harmful to health were likely to bc smokers themselves is interesting. This probably suggest that adolescent smokers are aware of the harmful effects of smoking but continue to smoke. A similar finding was reported by Young et al. (2007) who has reported that Australian smokers strongly support more regulatory control of tobacco.

Adolescents who reported having pocket money were more likely to be smokers than those who reported never having money. Having money could accord the adolescent purchasing power which may not be available when one does not have the money. The policy implication of this finding is not clear though. Probably, parental monitoring of how adolescents use their money may be useful.

While this study only aimed to assess adolescent smoking, it is also important to recognise that adolescents who engage in one unhealthy life style are also likely to engage in many other harmful lifestyles. Lee er al. (2007) have reported that adolescent smokers were more likely to be involved in physical fights, use of illicit drugs and carrying of weapons to schools.

This study had a number of limitations. The study design was cross sectional so it is not possible to assign causation to any of the factors identified as associated with adolescent smoking. Since the data were selfreported by the study participants, it is possible that some participants may have intentionally misreported or inadvertently misreported. Inadvertent misreporting could also occur when the study participant does not remember whether they had smoked with the 30 day period that the study questionnaire asked. Another limitation was that the study design did not incorporate verification of current smoking status by using biomarkers for assessinent of nicotine metabolites or exhaled carbon monoxide (Al-Delaimy, 2002; Chetiyanukornkul et al., 2004). In the case of blood or hair cotinine however, it has to be recognised too that environmental exposure to smoking may also produce a positive result (Sorensen et al., 2007). Furthermore, our study only recruited in-school adoleseents and therefore these findings may not be applicable to outof-school adolescents.

The data used in the current study were collected belore Tanzania committed itsell to the World Health Organization's Framework Convention on Tobacco Control (FCTC) in April 2007. It will be important to assess adolescent smoking pattems in a few years time so as to estimate the possible impact of the FCTC on Tanzania.

\section{Competing interests}

The authors declare they have no competing interests.

\section{Acknowledgements}

This study was conducted as part of the Global Youth Tobaeco Survey. The data used for the study were obtained from the Centres of Disease Control and Prevention (DC), Atlanta, Georgia, United States. The views expressed in the manuscript belong to the authors and not the CDC. Adamson S. Muula is the guarantor of the study.

\section{References}

Al-Delainy,W.K. (2002) Hair as a biomarker for exposure to tobacco smoke. Tobacco Control 11, 176-182.

Bricker, J.B., Peterson, A.V. Jr, Sarason, I.G., Andersen, M.R. \& Rajan, K.B. (2007) Changes in the influence of parents' and close friends' smoking on adolescent smoking transitions. Addiction Behaviour 32, 740-757.

Brook, J.S., Pahl, K. \& Ning, Y. (2006) Peer and parental influences on longitudinal trajectories of smoking among African Americans and 
Puerto Ricans. Nicotine Tobacco Research 8, 639-651.

CDC (2006) Use of cessation methods among smokers aged 16-24 years-United States, 2003. Morbidity and Mortality Weekly Report 5, 1351-1354.

Chetiyanukornkul, T., Toriba, A., Kizu, R., Kimura, K. \& Hayakawa, K. (2004) Hair analysis of nicotine and cotinine for evaluating tobacco smoke exposure by liquid chromatographymass spectrometry. Biomedical Chromatography 18, 655-661.

Gilliland, F.D., Islam, T., Berhane, K., Gauderman, W.J., McConnell, R., Avol, E. \& Peters, J.M. (2006) Regular smoking and asthma incidence in adolescents. American Journal of Respiratory Critical Care Medicine 174, 1094-1010.

Global Youth Tobacco Survey Collaborating Group. (2003) Differences in worldwide tobacco use by gender: findings from the Global Youth Tobacco Survey. Journal of School Health 73, 207-215.

Kokkevi, A., Richardson, C., Florescu, S., Kuzman, M. \& Stergar, E. (2007) Psychosocial correlates of substance use in adoleseence: a crossnational study in six European countries. Drug Alcohol Dependence 86, 67-74.

Kyrlesi, A., Soteriades, E.S., Warren, C.W., Kremastinou, J., Papastergiou, P., Jones, N.R. \& Hadjichristodoulou, C. (2007) Tobacco use among students aged 13-15 years in Greece: the GYTS project. BMC Public Health 7, 3.

Lee, L.K., Chen, P.C., Lee, K.K. \& Kaur, J. (2007) Violence-related behaviours among Malaysian adolescents: a cross sectional survey among secondary school students in Negeri Sembilan. Annals of the Academy of Medicine Singapore 36, 169-174.

Mathers, C.D. \& Loncar, D. (2006) Projections of global mortality and burden of disease from 2002 to 2030. PLoS Medicine 3, e442.

Mpabulungi, L. \& Muula, A.S. (2004) Tobacco use among high school students in Kampala, Uganda: questionnaire study. Croatian Medical Journal 45, 80-83.

Mpabulungi, L. \& Muula, A.S. (2006) Tobacco use among high school students in a remote district of Arua, Uganda. Rural Remote Health 6, 609.
Myers, M.G., Doran, N.M. \& Brown, S.A. (2007) Is cigarette smoking related to alcohol use during the 8 years following treatment for adolescent alcohol and other drug abuse? Alcohol and Alcoholism 42, 226-233.

Patton, G.C., Coffey, C., Carlin, J.B., Sawyer, S.M. \& Wakefield, M. (2006) Teen smokers reach their mid twenties. Journal of Adolescent Health 39, 214-220.

Primack, B.A, Gold, M.A., Land, S.R. \& Fine MJ. (2006) Association of cigarette smoking and media literacy about smoking among adolescents. Journal of Adolescent Health 39, 465-472.

Sorensen, M., Bisgaard, H., Stage, M. \& Loft S. (2007) Biomarkers of exposure to environmental tobacco smoke in infants. Biomarkers 12, 38-46.

The GTSS Collaborative Group (2006) A cross country comparison of exposure to secondhand smoke among youth. Tobacco Control 15 Suppl 2, ii4-19.

Wakefield, M., Terry-McElrath, Y., Emery, S., Saffer, H., Chaloupka, F.J., Szczypka, G., Flay, B., O'Malley, P.M. \& Johnston, L.D. (2006) Effect of televised, tobacco companyfunded smoking prevention advertising on youth smoking-related beliefs, intentions, and behaviour. American Journal of Public Health 96, 2154-2160.

Warren, C.W., Riley, L., Asma, S., Eriksen, M.P., Green, L., Blanton, C., Loo, C., Batchelor, S. \& Yach, D. (2000) Tobacco use by youth: a surveillance report from the Global Youth Tobacco Survey project. Bulletin of the World Health Organisation 78, 868-876.

Weden, M.M. \& Zabin, L.S. (2005) Gender and ethnic differences in the co-occurrence of adolescent risk behaviours. Ethnicity and Health 10, 213-234.

Young, D., Borland, R., Siahpush, M., Hastings, G., Fong, G.T., Cummings, K.M. ITC Collaboration (2007) Australian smokers support stronger regulatory controls on tobacco: findings from the ITC Four-Country Survey. Australia and New Zealand Journal of Public Health 31, 164-169. 